\title{
ARTICLE
}

치즈에서 부패를 일으키는 효모와 곰팡이의 다양성 및 저감법

\author{
김종희 · 김부민 · 정석근 · 오미화 \\ 농촌진흥청 국립축산과학원
}

\section{The Prevalence and Control of Spoilage Mold and Yeast in Cheese}

\author{
Jong-Hui Kim, Bu-Min Kim, Seok-Geun Jeong, and Mi-hwa Oh \\ National Institute of Animal Science, RDA
}

Received: July 31, 2017

Revised: September 5, 2017

Accepted: September 18, 2017

${ }^{*}$ Corresponding author :

Mi-hwa Oh

National Institute of Animal Science,

Rural Development Administration,

Wanju 55365, Republic of Korea.

Tel :+82-63-238-7379,

Fax :+82-63-238-7397,

E-mail : moh@korea.kr

Copyright @ 2017 Korean Society of Milk Science and Biotechnology.

This is an Open Access article distributed under the terms of the Creative Commons Attribution Non-Commercial License (http:// creativecommons.org/ licenses/by-nc/3.0) which permits unrestricted non-commercial use, distribution, and reproduction in any medium, provided the original work is properly cited.

\begin{abstract}
Cheese is an excellent substrate for yeast and mold growth. These organisms can cause cheese spoilage, resulting in significant food wastage and economic losses. In the context of cheese spoilage, the presence and effects of spoilage or pathogenic bacteria are well documented. In contrast, although yeasts and molds are responsible for much dairy food wastage, only a few studies have examined the diversity of spoilage fungi. This article reviews the spoilage yeasts and molds affecting cheeses in various countries. The diversity and number of fungi present were found to depend on the type of cheese. Important fungi growing on cheese include Candida spp., Galactomyces spp., Debaryomyces spp., Yarrowia spp., Penicillium spp., Aspergillus spp., Cladosporium spp., Geotrichum spp., Mucor spp., and Trichoderma spp.. In addition, several mold spoilage species, such as Aspergillus spp. and Penicillium spp., are able to produce mycotoxins, which may also be toxic to humans. There are many ways to eliminate or reduce toxin levels in foods and feeds. However, the best way to avoid mycotoxins in cheese is to prevent mold contamination since there are limitations to mold degradation or detoxifications in cheese. Chemical preservatives, natural products, and modified atmosphere packaging have been used to prevent or delay mold spoilage and improve product shelf life and food safety.
\end{abstract}

\section{Keywords}

spoilage mold, spoilage yeast, cheese

\section{서 론}

미생물은 유제품의 제조와 숙성기간 동안에 맛, 향기, 질감 및 외형에 중요한 역할을 한다(Lavoie et al., 2012). 유제품의 미생물학적 다양성과 개체량은 우유의 품질, 취급 및 열처리, 제조, 응결 처리 조건, 숙성기간의 온도 및 습도, 염분의 양, 제조 중 또는 제조 후 외인성 미생물에 노출된 정도에 따라 변화한다. 곰팡이는 일반적으로 산성조건 및 $30^{\circ} \mathrm{C}$ 에서 잘 증식하나 온도가 적당하면 건조식품에 서도 증식한다. 효모 또한 증식할 수 있는 $\mathrm{pH}$ 범위가 넓고(pH 2.0 8.2) 곰팡이와 마찬가지로 약산성 에서 잘자란다. 이들은 치즈 변질의 주요 원인이며, 여러 유형의 치즈에서 천이 과정에 중대한 영향을 미치는 것으로 알려져 있다(Swearingen et al., 2001; Nielwen et al., 2005).

유제품 부패와 관련한 세균의 종류와 특징에 대해서는 잘 보고되어 있으나(Brooks et al., 2012; Ledenbach and Marshall, 2010), 이와 관련한 효모와 곰팡이의 다양성에 관한 보고는 거의 없다 (Banjara et al., 2015; Kure, 2001; Kure and Skaar, 2000). 효모와 곰팡이는 스타터, 대기, 염수, 가공 장비 및 작업자 등 다양한 요인으로부터 유입되며(Borelli et al., 2006), 치즈의 맛과 풍미, 외형에 기여할 수 있으나, 모든 종들이 유익한 효과를 내는 것은 아니다.

치즈의 표면에 있는 특정 효모는 부패를 일으키거나, 치즈의 품질을 저하시켜 불쾌취 또는 유해 대사 산물을 유발할 수 있다(Atanassova et al., 2003). 효모가 병원체로 인정되지는 않지만, 다양한 종류의 
효모는 기회주의적 병원균으로 간주된다. 정상적인 상태에서 건강한 사람들에게는 위험하지 않으나, 점막, 피부, 호흡기, 중추 신경계 등 의 감염된 상태에서 질병을 유발할 수 있는 것으로 알려져 있다 (Fleet and Balia, 2006). 실제로 다양한 치즈에서 Candida albicans, Candida tropicalis, Candida krusei 및 Candida glabrata 등의 질병 관련 효모종이 확인되었다(EI-Sharoud et al., 2009; Gadaga et al., 2000; Wanderley et al., 2013).

곰팡이는 종종 특정 품종의 치즈에 첨가되어 특이적 외형, 품질의 일 관성 및 풍미를 제공하고, 유통 기한을 연장시킨다(Haasum and Nielsen, 1998). 그러나 치즈를 오염시키는 2차 곰팡이는 건강 위험 을 초래할 수 있는 잠재적 위험요소이기도 하다(Creppy 2002; Sengun et al., 2008). 일부 독성 유발 곰팡이는 일반적으로 '마이 코톡신'이라고 불리는 2 차 대사산물을 생산할 수 있다. 치즈에서 가 장 위험한 독소는 오크라톡신A(OTA)와 아플라톡신M1(AFM1)으로 알려져 있다(Hymery et al., 2014). 이들은 직접적인 치즈 오염 또 는 사료 오염으로 치즈 제조에 사용되어지는 우유의 간접적 오염을 통해 Aspergillus, Fusarium, Penicillium 속과 같은 원하지 않는 곰팡이로부터 생성된다.

2011년 이후 EU, 미국, 호주, 뉴질랜드 등 낙농선진국과의 FTA 체 결로 수입치즈의 양이 큰 폭으로 증가하였다. 낙농진흥회의 통계에 따르면 국내 1 인당 치즈 소비량은 2005년 $1.5 \mathrm{~kg}$ 에서 2015년 2.6 $\mathrm{kg}$ 으로 약 73\% 증가하였다(KDC, 2016). 이렇듯 다양한 나라에서 수입된 치즈가 우리나라의 전 연령층에 의해 빠르게 소비되고 있는 현실을 고려해 볼 때, 나라마다 다른 조건에서 제조된 수입치즈의 안 전성 문제는 국민의 건강과 매우 직결되어 있다. 게다가 최근 식품의 약품안전처는 비살균원유로 제조된 자연치즈 제조 및 수입을 허용하 는 “축산물의 가공기준 및 성분규격" 일부 개정(안)을 고시하였다(Korea MFDS, 2016).

따라서 본 논문에서는 치즈의 부패와 관련된 효모 및 곰팡이의 다양 성과 이들의 성장을 예방하거나, 곰팡이 독소량을 감소시키기 위해 사용할 수 있는 잠재적 저감방법에 대해 논의하고자 한다.

\section{본 론}

\section{1. 치즈 부패를 일으키는 효모}

효모는 다양한 종류의 치즈에서 맛과 향미에 기여하지만, 항상 유익 한 것은 아니다. 효모에 의한 치즈 부패는 치즈 표면에 효모 집락의 가시적인 성장으로 불쾌한 색과 냄새, 맛, 질감의 변화를 일으키고, 효모가 생성하는 가스로 인한 포장재의 변형이 발생되기도 한다. 현 재까지 치즈의 부패 효모에 대한 보고가 많지 않은데, 이는 특정 효 모종의 존재가 유익하게 만들거나, 유해하게 만드는 때를 결정하기 가 쉽지 않기 때문일 수 있다. 효모 중 Geotrichum candidum, Kluyveromyces marxianus, Yarrowia lipolytica, Pichia mem- branaefaciens, 및 Debaryomyces hansenii는 독일의 프레시 치 즈에서 불필요한 감각 변화를 일으켰으며, 저자는 효모향, 쓴맛, 과 실향 등의 인식할 수 있는 이취를 내기 위해서는 종에 따라 적합한 농도가 필요하다고 보고하였다(Engel, 1986). 예를 들면 G. candi$d u m$ 는 $10^{3} \sim 10^{4} \mathrm{CFU} / \mathrm{mL}$ 의 농도로 치즈에서 변질을 일으켰지만 Y. lipolytica로 인한 관능적 변화는 $10^{5} \sim 10^{6} \mathrm{CFU} / \mathrm{mL}$ 의 농도가 되어야 탐지되었다.

코타지(cotaage) 치즈 중 부패 효모는 여러 연구자에 의해 조사되었 다(Table 1). 유통 기한 내에 Sporobolomyces roseus 및 Trichosporon 속은 코타지 치즈 표면에 바이오필름을 형성하였다(Brocklehurst and Lund, 1985). Debaryomyces hansenii, Candida sake, Candida zeylanoides, Cryptococcus albidus, Cryptococcus laurentii 및 $Y$. lypolytica도 부패한 코타지 치즈에서 분리 되었다(Engel, 1986). Fleet과 Mian(1987)은 코타지 치즈에서 D. hansenii, C. albidus 및 Rhodotorula glutinis를 분리하였다. 페 타(feta) 치즈의 부패는 주로 치즈 샘플의 팽창으로 인지되었으며, Kluyveromyces blattae, Kluyveromyces thermotolerans 및 Candida sphaerica가 가스를 생성한 것으로 밝혀졌다(Vivier et al., 1994). 덴마크에서 부패된 페타 치즈의 팽창은 Torulaspora delbrueckii에 의해 발생하였고, 높은 농도의 D. hansenii는 강력 한 누룩 냄새의 원인이었다. 고농도의 Y. lipolytica는 지방의 분해 로 인한 치즈의 원치 않는 질감을 초래하였고, C. sake, C. intermedia, K. marxianus 및 Kluyveromyces lactis도 부패한 페타 치즈로부터 분리되었다(Westall and Filtenborg, 1988). 이탈리아 의 스트라치노(stracchino) 치즈의 부패는 나쁜 냄새와 가시적 미생 물 집락으로 감지되었다. 원인 효모종은 T. delbrueckii, D. hansenii, K. marxianus 및 Saccharomyces cerevisiae로 확인되었 으며, C. intermedia, Trichosporon cutaneum, C. laurentii 및 G. candidum도 분리되었다(Sarais et al., 1996). 터키의 다양한 화이트 치즈로부터 부패를 일으키는 12종 효모균주가 분리되었다 (Yalcin and Ucar, 2009). D. hansenii (32.6\%), K. marxianus (18.5\%), Y. lipolytica (17.4\%)가 가장 많이 분리되었으며, Pichia, Torulaspora, Williopsis, Galactomyces 속도 검출되었다. 최근 에 프랑스의 부패된 치즈 25종에서 41종의 효모와 곰팡이가 분리되 었으며, Pichia fermentans와 Trichosporon asahip가 가장 흔한 효모종이었다. 치즈 종류별로는 크림 치즈에서는 C. inconspicua, K. lactis가 가장 많이 발견되었고, 하드치즈에서는 D. hansenii, Sporodiobolus salmonicolor, Y. lipolytica가 발견되었다. 프레 시 치즈에서 가장 많은 부패 효모가 분리되었으며, T. asahii, $K$. marxianus, P. fermentans 가 원인종이었다(Garnier et al., 2017). 한편, 치즈의 스타터(starter)로 사용되는 젖산균이 부패 효모 발생 의 잠재적 원인일 수 있다. Streptococcus thermophilus와 같은 고온성 스타터로 만든 치즈는 Kluyveromyces 및 Saccharomyces 
속과 같은 갈락토오스 발효 효모에 의한 손상에 특히 취약하다. 이것 은 고온성 유산균이 유당의 포도당 부분은 대사하지만, 갈락토오스 는 배지로 배출시키기 때문이다(Lourens-Hattingh and Viljoen, 2001). Lactococcus lactis와 같은 중온성 스타터로 만든 치즈도 갈락토오스 발효 효모에 의한 손상을 받기 쉽다. Lactococci도 고온 성 젖산균처럼 치즈에서 유당으로부터 갈락토오스를 분비할 수 있기 때문이다(Liu et al., 1998). 따라서 효모 성장으로 인한 치즈 부패 를 제어하기 위한 연구가 필요하다.

\section{2. 치즈 부패를 일으키는 곰팡이와 관련 독소}

\section{1) 곰팡이}

곰팡이로 인한 식품 손상은 전 세계적으로 식량과 경제적 손실의 주 요 원인 중 하나이다. 치즈 속 곰팡이의 생장은 주로 낮은 온도와 산소농도, $\mathrm{pH}$, 수분활성에서 생육할 수 있는 특성 때문이다. 곰팡이 는 유리 지방산에 종종 내성을 가지며, 지방 분해능이 있어 치즈에 부패를 일으킬 수 있다(Hocking, 1997). 곰팡이 오염은 미생물의 증식(집락형성)으로 인해 "고양이 털"과 같은 형태로 나타나며, 곰팡 이 대사에 따른 불쾌한 냄새와 맛, 가스 생산, 질감의 변화가 나타난 다(Ledenbach and Marshall, 2010). 치즈에서 흔히 분리되는 부 패 균류에는 Penicillium, Aspergillus, Cladosporium, Geotrichum, Mucor 속 및 Trichoderma 속이 있으며(Taniwaki et al., 2001), Aspergillus와 Penicillium 속의 몇 가지 곰팡이 변종은 인 간에게 독성이 있는 곰팡이독소을 생산할 수 있다(Northolt et al., 1980).

Penicillium 속은 치즈에 가장 많이 존재하며, 모든 치즈의 유형에 서 발생하는 것으로 밝혀졌다(Table 1). 스페인에서 생산되는 다양 한 종류의 우유로 만든 상업용 치즈 52개 시료(프레시 치즈 10 개, 세미-하드 치즈 17개, 하드 치즈 25개)에서 Penicillium 속이 연구 된 바 있다(Banjara et al., 2015). Penicillium 속은 시료의 63\% 에서 확인되었으며, Mucor속 27\%, G. candidum 17\%, Cladosporium herbarum $10 \%$ 에서 검출되었고, 숙성된 기간이 길수록 Penicillium 속의 발병률은 높아졌다. 치즈에서 발견되는 Penicillium 속의 대부분은 Fasciculata와 Brevicompacta section에 속한다. P. commune, P. discolor, P. nordicum, P. palitans, P. solitum와 같은 Fasciculata section에는 유제품에서 잘 알려진 부패 원인종들이 많이 포함되어 있다(Kure, 2001; Ledenbach and Marshall, 2010; Pitt and Hocking, 2009). P. brevicompactum, P. bialowiezense, P. salamii P. spathulatum과 같은 Brevicompacta section에 포함된 종은 냉장 온도에서도 잘 자라며, 종 종 호건성 곰팡이로 분류된다(Pitt and Hocking, 2009).

눈에 보이는 치즈의 오염원으로 Penicillium roqueforti, P. commune 및 P. solitum이 가장 잘 알려져 있다. 치즈 생산에 관여
하는 P. roqueforti 와 P. commune는 호주 및 뉴질랜드 치즈에서 발견되는 가장 흔한 곰팡이 종이다(Hocking, 1994). P. roqueforti 는 블루(blue) 치즈 생산에 사용되지만, 동시에 부패 곰팡이로도 잘 알려져 있다(Pitt and Hocking, 2009). 이 종은 오염된 치즈에서 발견된 적이 있으며, 주로 체다(chedda) 치즈의 주요 오염 원인종이 다(Tsai et al., 1988). P. roqueforti는 이산화탄소가 많은 대기에 서도 성장이 가능한 것으로 보인다. Haasum과 Nielsen(1998)의 연구에서 P. roqueforti는 산소가 낮고 이산화탄소 농도가 높은 대 기에 노출되었으나, 거의 영향을 받지 않았음을 보여주었다. 또한 약 산성 방부제에 대한 내성도 가지는 것으로 나타났다. 얄스버그 (Jarlsberg) 치즈는 숙성되는 동안에 이산화탄소와 프로피온산을 모 두 생산하는 선택적 환경을 조성하며, 이에 치즈로부터 분리된 전체 종의 39.5\%를 P. roqueforti var. roquefort가 차지하고 있다(Filtenborg et al., 1996). P. commune는 카망베르(camembert), 브 리(brie)와 같은 치즈의 생산에 사용되는 P. camemberti의 야생형 조상이며, 식품에서 흔한 오염 미생물이기도 하다(Pitt and Hocking, 2009). Lund 등(1995)은 여러 나라에서 생산된 다양한 치즈를 조사 한 결과 P. commune가 치즈의 주요 오염원임을 보여주었는데, 어 떤 경우는 371 균체 중 $42 \%$ 를 차지하기도 하였다. 또한 P. commune는 체다 치즈 부패의 주요 원인 중 하나인 것으로 밝혀졌다 (Hocking and Faedo, 1992). 부패된 체다 치즈의 표면에는 검은 얼룩이 나타날 수 있는데, 가장 관련 있는 속은 Cladosporium( $C$. cladosporioides 및 $C$. herbarum), Penicillium (P. commune 및 P. glabrum) 및 Phoma이다(Hocking and Faedo, 1992). 최 근 Garnier와 그의 동료들은 부패한 12 개 하드치즈에서 곰팡이를 분리하고, 유전자의 ITS(Internal Trascribed Spacer) 영역을 이용 하여 동정하였다(Garnier et al., 2017). 그 결과, P. commune와 P. bialowiezense가 가장 많이 발견되었으며, P. antarcticum, P. discolor, P. nalgiovense, P. nordicum, P. palitans P. roqueforti, P. solitum, Mucor circinelloides, $M$. racemosus, $M$. spinosus, Thamnidium elegans도 다수 확인되었다. 게다가 Brevicompacta section인 P. brevicompactum도 발견되었다. 이 종은 스페인 치즈와 노르웨이 치즈공장의 실내 환경에서도 종종 보고되었 다(Barrios et al., 1998; Kure et al., 2004). 치즈는 P. solitum의 주요 서식처이며, 부패된 상업용 치즈(retail cheese)에서 가장 흔히 분리된 종들 중 하나이다(Hocking and Faedo, 1992). Hocking (1994)에 따르면 P. solitum은 남아프리카 공화국과 호주 치즈에서 발견되는 곰팡이의 주종이며, C. herbarum은 일반적으로 호주 치 즈공장의 실 곰팡이 결함이 있는 치즈와 관련이 있다고 보고하 였다. 노르웨이에서 가장 많이 생산되는 세미-하드 치즈인 노베 지아(Norvegia) 치즈와 얄스버그 치즈에서 가장 많이 발생하는 곰팡 이는 Penicillium roqueforti var. roqueforti, P. commune, P. palitans 및 $P$. solitum이었다(Casalinuovo et al., 2015). 이 4 
종은 노베지아 치즈 분리종의 $69.8 \%$ 를 차지했으며, 얄스버그 치즈 의 분리종의 $81.0 \%$ 를 차지하였다. Phoma glomerata는 최근 모짜 렐라(mozzarella) 치즈의 비정상적인 착색을 일으킨다고 보고되었 다(Casalinuovo et al., 2015).

\section{2) 곰팡이 독소}

카망베르(camembert) 치즈와 로크포르(roquefort) 치즈와 같은 일부 치즈에는 의도적으로 곰팡이를 넣는다. 이러한 종류의 치즈를 제조할 때 스타터는 낮은 독성을 가진 곰팡이 종을 선택해야 하며, 자연적으로 생성된 곰팡이가 있는 치즈는 곰팡이독소의 위험 때문 에 섭취하지 않아야 한다. 낙농제품에서 특정 곰팡이의 대사를 통해 생산된 곰팡이 독소는 두 가지 경로인 (1) 낙농 젖소가 곰팡이독소 이 함유된 사료를 먹은 뒤 아플라톡신 $\mathrm{M}_{1}\left(\mathrm{AFM}_{1}\right)$ 과 같은 독소를 가 진 우유를 생산하는 간접 오염, (2) 우발적 또는 의도적인 곰팡이 증식에 따른 오염을 통해 일어난다(Segun et al., 2008). 치즈에서 발견되는 곰팡이 독소 중 페니트렘 $\mathrm{A}(\mathrm{penitrem} \mathrm{A)와} \mathrm{시트리닌(ci-}$ trinin), 스테리그마토시스틴(sterigmatocystin), 로큐포르틴C(roquefortine C), 아플라톡신(aflatoxin)은 안정적으로 존재하는 반
면, 파툴린(paturin)과 페니실산(penicillic acid), PR독소(PR toxin)는 안정적이지 않다. 소량의 파툴린과 페니실산은 경구독성이 낮기 때문에 공중 보건의 관점에서 크게 중요한 문제는 아니지만, 아플라톡신의 경우 발암성 때문에 충분히 우려할 만하다. 식품 중 곰팡이 독소생산은 온도와 식품 기질, 곰팡이, 다른 환경요인의 영 향을 받을 수 있다. 음식과 사료에서 곰팡이 증식을 막고, 독소를 분해하거나 해독하는 다양한 방법이 여러 연구자들에 의해서 보고 되었다. 그러나 독소 분해 또는 해독은 분명히 한계가 있기 때문에 곰팡이독소를 피하는 가장 좋은 방법은 곰팡이 오염 자체를 예방하 는 것이다.

\section{3) Aflatoxins $M_{1}$}

가장 많이 연구된 곰팡이독소은 아플라톡신으로 다양한 식품에서 Aspergillus flavus, A. parasiticus 및 A. nomius 곰팡이 균주에 의해 생성되는 자연 발생 독소 군이다. 자연적으로 생산되는 4 가지 주요 아플라톡신은 $\mathrm{B}_{1}, \mathrm{~B}_{2}, \mathrm{G}_{1}$ 및 $\mathrm{G}_{2}$ 이다( Creppy, 2002). 그 중에 서도 아플라톡신 $\mathrm{B}_{1}\left(\mathrm{AFB}_{1}\right)$ 은 가장 많이 생성되는 곰팡이 독소이며, 포유동물에서 가장 강력한 천연 발암물질로 알려져 있다(Rosi et

Table 1. Diversity of spoilage yeast and mold species from variety of cheese types

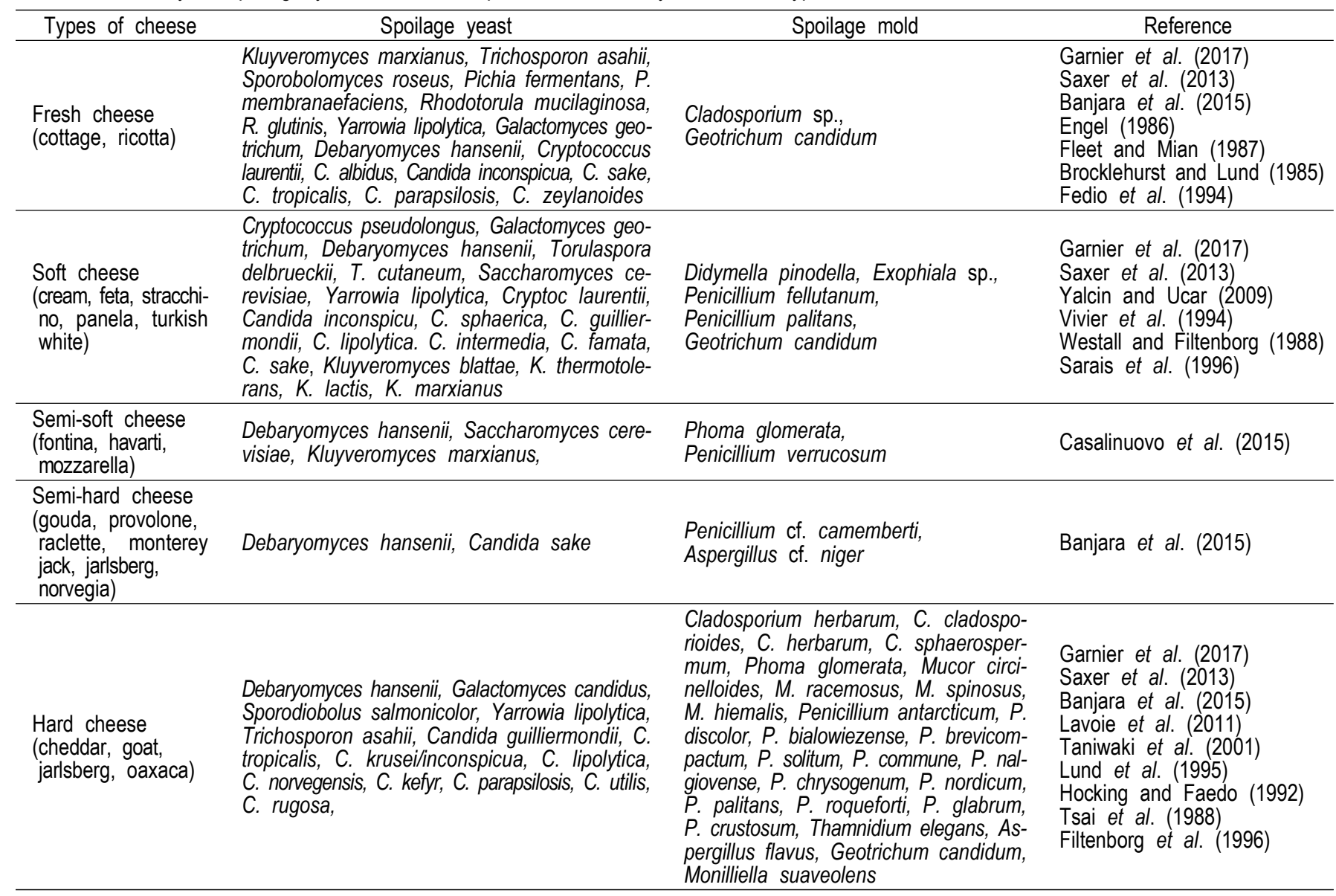




\section{al., 2007).}

$\mathrm{AFM}_{1}$ 과 $\mathrm{AFM}_{2}$ 는 $\mathrm{AFB}_{1}$ 과 $\mathrm{AFB}_{2}$ 의 모노히드록시화된 유도체이며, $\mathrm{AFB}_{1}$ 이나 $\mathrm{AFB}_{2}$ 로 오염된 물질을 섭취한 사람을 포함하여 수유 중인 동물의 젖에서 생성되고 배설된다(Lopez, 2001). $\mathrm{AFB}_{1}$ 의 첫 섭취 후 12 시간 이내에 우유에 나타날 수 있으며, 오염된 공급원의 중단 후, $\mathrm{AFM}_{1}$ 은 72 시간 이내에 사라졌다. 이전 연구에서 우유의 $\mathrm{AFM}_{1}$ 함량과 식이를 통한 $\mathrm{AFB}_{1}$ 의 소비량 사이에는 선형 관계가 있음이 밝혀졌고, 동물 사료에 존재하는 $\mathrm{AFB}_{1}$ 의 약 0.3 6.2\%는 우유 생성 과정에서 $\mathrm{AFM}_{1}$ 으로 전환된다고 예측되고 있다(Creppy, 2002).

다양한 치즈에서 $\mathrm{AFM}_{1}$ 의 발생을 보고한 연구들이 많이 있다. $\mathrm{AFM}_{1}$ 은 낙농 산업에서 사용되는 열처리인 저온 살균 및 멸균과 다양한 유제품의 가공 및 저장 방법에도 영향을 받지 않았다(Gurbay et al., 2006; Unusan, 2006; Prandini et al., 2009). 몇몇 연구자들은 $\mathrm{AFM}_{1}$ 이 다양한 종류의 치즈를 숙성시키고 저장하는 동안 안정적인 정량적 수치를 보인다고 보고하였으나(Oruc et al., 2007), Colak (2007)은 흰색치즈 숙성기간 동안 $\mathrm{AFM}_{1}$ 이 9.8\% 감소하는 것을 보 여주었으며, Purchase 등(1972)은 저온 살균이 우유 중 $\mathrm{AFM}_{1}$ 함량 을 $32 \%$ 감소시키는 것으로 보고하였다. 또, 다른 연구에서는 우유 중 $\mathrm{AFM}_{1}$ 함량이 $0^{\circ} \mathrm{C}$ 에서 4 일 후 $40 \%, 6$ 일간 저장 후 $80 \%, 21^{\circ} \mathrm{C}$ 에 서 2주간 저장 후 34\% 감소하였다(Heimbecher et al., 1988). 치 즈 제조 과정에서 우유와 유청 사이의 $\mathrm{AFM}_{1}$ 분포에 대한 결과는 다 양하였다(Lopez et al., 2001). 이러한 다양성은 치즈의 유형, 적용 된 치즈 제조 공정, 우유 오염의 종류와 정도, 사용된 분석 방법과 관련이 있었다(Blanco et al., 1988). Lopez 등(2001)은 인위적으 로 $\mathrm{AFM}_{1}$ 오염 우유를 사용하여 치즈를 제조한 뒤 실험한 결과, 유청 에서 60\%로 가장 많은 독소가 남아있었으며, 치즈에는 $40 \%$ 가 남아 있었다고 보고하였다. 그러나 일부 다른 연구자들은 $\mathrm{AFM}_{1}$ 이 우유에 가장 많이 분포(66 80\%)되어 있다고 보고하였다(Marshaly et al., 1986).

$\mathrm{AFM}_{1}$ 의 독성은 $\mathrm{AFB}_{1}$ 보다 낮지만, 그 세포독성, 유전독성 및 발암성 많은 연구에 의해 보고되었다(Polychronaki et al., 2007). WHO (World Health Organization)의 국제암연구기구(IARC)는 2002 년 $\mathrm{AFM}_{1}$ 을 2군 발암 물질에서 1군 발암물질로 변경하였다(IARC, 2002). 따라서 몇몇 국가는 소비자 보호를 위해 우유 및 유제품에서 $\mathrm{AFM}_{1}$ 의 최대 허용 수준을 제안하는 규정을 가지고 있다. 치즈에서 $\mathrm{AFM}_{1}$ 의 한계는 국가별로 매우 다양하다. 호주는 성인 우유에서 0.05 , 아이들 우유에서 $0.01 \mu \mathrm{g} / \mathrm{kg}(\mathrm{ppb})$ 으로 규정하고 있으며, 버 터, 치즈, 분유에도 각각 $0.02,0.25,0.4 \mathrm{ug} / \mathrm{kg}$ 의 $\mathrm{AFM}_{1}$ 의 허용한 계를 가지고 있다. 스위스, 뉴질랜드, 터키, 온두라스 등의 국가에서 도 치즈에서 $0.2 \sim 0.25 \mu \mathrm{g} / \mathrm{kg}$ 수준으로 $\mathrm{AFM}_{1}$ 을 규제하고 있다. 우 리나라의 경우, 우유류에서 $\mathrm{AFM}_{1}$ 허용기준은 $0.5 \mu \mathrm{g} / \mathrm{kg}$ 이하로 규 정하고 있으나, 치즈에서의 규제는 없는 실정으로 국민의 안전을 위 해서는 규정이 신설되어야 할 것으로 보인다.

\section{3. 치즈에서 효모 및 곰팡이 저감법}

다양한 화학보존제 및 천연물은 치즈의 곰팡이 발생을 억제하기 위 해 적용되었다. 아세테이트, 소르베이트, 벤조에이트 및 프로피오네 이트와 같은 약산 및 그의 염은 보존제로 널리 사용된다(Brul and Coote, 1999). 소르빈산칼륨은 식용으로 승인된 소금 중 하나이며, 항진균성이 많은 저자들에 의해 입증되었다(Flores et al., 2010; Sayanjali et al., 2011). 소르빈산칼륨은 Penicillium digitatum 과 P. italicum을 조절하는데 가장 효과적이었다(Valencia-Chamorro et al., 2008). Aspergillus flavus는 티몰과 유제놀, 카르바 트롤, 소르빈산나트륨, 아황산수소나트륨, 벤조산나트륨(pH 3.5)보 다 바닐린이나 시트랄에 더 높은 민감도를 보였다(López-Malo et al., 2005). Garnier 등(2017)은 치즈에서 분리한 곰팡이 4종 및 효 모 3종에 대하여 프로피온산칼슘, 벤조산나트륨, 소르빈산칼륨의 항 균효과를 평가하였다. 그 결과, 소르빈산칼륨와 벤조산나트륨은 각 각 0.1 0.5 g/L, 0.3 3 g/L의 농도에서 테스트된 진균류의 생장을 저해시켰다(Garnier et al., 2017). 그러나 소르빈산염의 사용은 일 부 Penicillium 속 균류에 의해 탈카르복실화 된 후 등유 냄새가 나 는 풍미이상을 유발할 수 있기 때문에 이러한 기술은 치즈의 사용에 제한적이다(Liewen, 1992). 맛과 풍미에 부정적인 영향 외에도 소 비자들은 자연 및 유기농 제품을 선호하여 식품에 방부제 및 화학물 질을 사용하는 것에 대해 우려하고 있다. 따라서 최근에는 화학적 처리 를 대체하기 위한 천연방부제 개발에 상당한 관심이 집중되고 있다. 나타마이신은 Streptomyces natalensis 또는 Streptococcus lactis의 자연 균주에 의해 생산된 폴리엔마크롤라이드(polyene macrolide antibiotics) 그룹의 천연살균제이며, $\mathrm{EU}$ 식품 첨가물 목록 에 E-235로 등록되어 있다. 식품 첨가물에 관한 Regulation 1333/ 2008/EC에 따르면, 나타마이신은 특정 치즈 및 건조된 소시지 제품 의 표면 보존제로 표면으로부터 깊이 $5 \mathrm{~mm}$ 이상에서는 검출되어서 는 아니되며, 최대 $1 \mathrm{mg} / \mathrm{dm}^{2}(20 \mathrm{mg} / \mathrm{kg})$ 이하의 농도 수준에서 승 인되었다. 치즈에서 곰팡이 성장을 지연시키는데 있어서 나타마이신 의 효과는 종종 보고되었다. 1990년도 이후에는 포장 또는 포장 재 료에 살균제 또는 보존제를 첨가시킴으로써 치즈 표면의 곰팡이 발 생을 억제하려는 허들기술이 시도되었다. 나타마이신과 포장재를 적 용한 터키의 카샤르(kasar) 치즈 시료에서 5개월 숙성기간 동안 곰 팡이가 발생하지 않았다고 보고되었다(Var et al., 2006). 유사한 효 과가 Türe 등(2011)에 의해서도 보고되었다. 신선한 카샤르 치즈 표 면에 접종된 P. roqueforti와 A. niger에 대하여 메틸셀룰로오즈와 밀글루텐 필름에 첨가된 나타마이신이 A. niger를 $2 \log \mathrm{cfu} / \mathrm{g}$ 감소 시켰다. 또한 고다(gouda) 치즈, 에담(deam) 치즈, 살로이오(saloio), 즐라또(zlato) 및 고르곤졸라(gorgonzola)와 같은 다양한 치즈에서 도 나타미이신의 효과가 입증된 바 있다(De Oliveira et al., 2007; Fajardo et al., 2010; Hanusova et al., 2010). 일반적으로 곰팡 이에 대한 나타마이신의 최소 억제 농도(MIC)는 0.5 6 $\mu \mathrm{g} / \mathrm{mL}$ 이 
지만, 일부 종은 10 25 $\mu \mathrm{g} / \mathrm{mL}$ 가 필요하며, 대부분의 효모는 1 5 $\mu \mathrm{g} / \mathrm{mL}$ 의 농도로 억제된다(Delves-Broughton et al., 2005). 그러 나 나타마이신을 식품 표면에 적용하는 것이 항상 효과적이지는 않 다(Fucinos et al., 2012). 고체배지에서 5\%의 시남알데히드와 $0.5 \%$ 의 나타마이신이 함유된 글리아딘 필름은 Penicillium 속, Alternaria solani 및 Colletotrichum acutatum에 대해 각각 $33 \%$, $28 \%, 16 \%$ 의 항균활성을 보여주었다. 그러나 다른 곰팡이에 대한 억 제에서 유의한 차이는 발견되지 않았다(Balaguer et al., 2014). 동 일 저자는 소프트 치즈와 세미-하드 치즈에 위와 동일한 조건의 필름 으로 항균활성을 시험하였다. 그 결과, Penicillium 속은 두 치즈 모두에서 자랐으며, 소프트치즈는 필름 경계면을 포함하여 내부까지 곰팡이 생장을 저해하였으나, 세미-하드 치즈는 필름 경계면에서만 곰팡이 생장을 억제하였다. 글리아딘과 같은 생체 고분자로 만들어 진 식용 필름의 항균효과는 물의 압력에 크게 의존적이기 때문에, 곰 팡이의 생장 억제에 있어서 수분 활성도가 다른 두 치즈에서 차이를 보인 것으로 사료된다. 따라서 치즈의 수분 활성도가 높을수록 이들 필름에 노출되었을 때 곰팡이 억제가 더 높다고 결론지었다(Balaguer et al., 2014).

항균성을 지닌 특정 허브나 향신료 또는 오일과 같은 천연식품 추출 물도 치즈 등 다양한 식품에서 곰팡이의 증식을 방지하기 위해 고대 부터 사용되어져왔다. 치즈 제조 시 첨가된 알로에 베라(15\%)는 Penicillium citrinum의 생장을 37.3\% 억제하였다(Sajadi and Bahramian, 2015). 경쟁적 미생물의 존재는 또한 곰팡이 성장과 곰팡이독소 생산을 억제할 수 있다(Bullerman et al., 1984). C. herbarum, P. caseifulvum과 P. commune와 같은 부패 미생물 은 2차 스타터인 P. camemberti, G. candidum의 생존에 민감하 였다(Decker and Nielsen, 2005). 또한, 유산균 및 기타 박테리아 와 그 대사산물은 곰팡이의 성장 및 곰팡이독소 생산을 방지하는 식 품에 사용되는 천연 생물학적 조절제로서 큰 가능성을 가지고 있다 (Schillinger and Villarreal, 2010; Lynch et al., 2014).

화학적 보존제의 잠재적 위해성을 줄일 수 있는 새로운 방법으로 지 난 20년 동안 가장 실용적인 기술로서 주목을 받은 것은 $\mathrm{MAP}(\mathrm{Mo}-$ dified Atmosphere Packaging) 이다(Nielsen, 2000). 이 기술은 신선한 제품의 품질유지, 제품의 이미지 개선, 유효 기간 연장, 첨가 제 및 방부제의 최소 사용과 같은 여러 가지 장점이 있어 치즈의 저 장 및 보관에 많이 이용되었다(Garabal et al., 2010). 코타지 치즈 (Fedio et al., 1994)와 얇게 썬 모짜렐라 치즈(Alves et al., 1996) 에서 불필요한 효모의 성장을 제어하는 방법으로 MAP를 적용하였 고, 두 저자는 각각 $50 \%(\mathrm{v} / \mathrm{v}) \mathrm{CO}_{2}: 50 \%(\mathrm{v} / \mathrm{v}) \mathrm{N}_{2}$ 또는 $100 \%(\mathrm{v} / \mathrm{v})$ $\mathrm{CO}_{2}$ 를 함유하는 수정된 기체에서의 포장이 효모 성장을 완전히 억 제하거나 유도기를 지연시켜 이로 인한 부패과정을 늦춘다는 것을 보여 주었다. 그러나 MAP의 이상적인 대기조성은 치즈의 종류에 따 라 다르다. 그리스의 유청 치즈는 $40 \% \mathrm{CO}_{2} / 60 \% \mathrm{~N}_{2}, 60 \% \mathrm{CO}_{2} /$
$40 \% \mathrm{~N}_{2}$ 에서 곰팡이와 효모의 성장을 억제하였다(Dermiki et al., 2008). 크로탱 드 샤비낼(crottin de chavignol) 치즈의 곰팡이 생 장에서 15 주 동안 대조군(공기)는 1 일에서 $6 \mathrm{log} \mathrm{cfu} / \mathrm{g}$ 의 생장을 보인 반면, $20 \% \mathrm{CO}_{2} / 80 \% \mathrm{~N}_{2}$ 조건의 경우 15 일 후에 $2 \mathrm{log} \mathrm{cfu} / \mathrm{g}$ 가 생성되었다(Esmer et al., 2009).

\section{결 론}

곰팡이와 효모는 치즈 변질의 주요 원인임에도 불구하고, 이들의 다 양성에 관한 자료는 많지 않다. 특히 곰팡이 오염은 곰팡이가 생산하 는 독소의 위해성 때문에 정확한 식별(동정)과 제어가 필요하다. 각 국에서 다양한 종류의 부패한 치즈에서 부패를 유발하는 효모 및 곰 팡이가 확인되었으며, 치즈 종류와 물성에 따라 미생물 종류와 수(정 량)의 차이가 있었다. 많은 나라에서 제품 보관 수명과 안전성을 높 이기 위해 치즈의 효모 또는 곰팡이에 의한 부패를 방지하거나 지연 시키기 위한 행정적 규제와 다양한 저감방법을 모색해 왔다. 화학물 질을 이용한 저감방법은 맛과 풍미에 대한 부정적 영향을 줄 뿐 아니 라, 소비자 거부감이 심하여 최근에는 천연방부제를 개발하는데 상 당한 노력을 기울이고 있다. 천연방부제인 나타마이신은 현재 식품 산업에 적용되어지고 있지만, 허용되는 농도범위가 기존 연구에서 항균효과를 보였던 농도보다 낮아서 실효성에 의문이 제기된다. 게 다가 대부분의 천연물질은 낮은 안정성, 좁은 항균 스펙트럼 및 고비 용 등 여러 가지 제약으로 인하여 아직까지 이용이 제한되고 있다. 그러나 항균활성 필름 또는 MAP와 같은 물리적 제어 기술과 접목한 새로운 기술이 치즈의 보존에 폭넓게 이용될 수 있을 것으로 기대된 다. 우리나라의 경우 아직까지 치즈 중 유해미생물을 제어하기 위한 기술의 응용정도가 많이 미약한 실정이다. 또한 소비되는 치즈 종류 도 국가별로 차이가 있기 때문에, 우리나라 치즈에 적용하기 위해서 는 그 효과에 대한 검증이 반드시 수반되어야 할 것이다. 또한 그에 앞서 우리나라에서 제조된 치즈의 생태학적 지역적 특성과 부패미생 물의 상관성 등에 대한 연구가 선행된다면 국내 치즈의 안전성 확보 에 도움이 될 것으로 사료된다.

\section{감사의 글}

본 연구는 농촌진흥청 연구사업(목장형 유가공품의 유해미생물 다중 제어기술 개발, PJ01257601)과 2017년도 농촌진흥청(국립축산과 학원) 박사후연수과정 지원사업에 의해 이루어진 것임.

\section{References}

Atanassova, M., Choiset, Y., Dalgalarrondo, M., Chobert, J. M., Dousset, X. and Ivanova, I. 2003. Isolation and par- 
tial biochemical characterization of a proteinaceous antibacteria and anti-yeast compound produced by Lactobacillus paracasei subsp. paracasei strain M3. Int. J. Food Microbiol. 87:63-73.

Balaguer, M. P., Fajardo, P., Gartner, H., Gomez-Estaca, J., Gavara, R., Almenar, E. and Hernandez-Munoz, P. 2014. Functional properties and antifungal activity of films based on gliadins containing cinnamaldehyde and natamycin. Int. J. Food Microbiol. 173:62-71.

Banjara, N., Suhr, M. J. and Hallen-Adams, H. E. 2015. Diversity of yeast and mold species from a variety of cheese types. Curr. Microbiol. 70:1-9.

Barrios, M. J., Medina, L. M., Lopez, M. C. and Jordano, R. 1998. Fungal biota isolated from Spanish cheeses. J. Food Saf. 18:151-157.

Borelli, B. M., Ferreira, E. G., Lacerda, I. C. A., Franco, G. R. and Rosa, C. A. 2006. Yeast populations associated with the artisanal cheese produced in the region of Serra da Canastra, Brazil. World J. Microbiol. Biotechnol. 22:1115-1119.

Brocklehurst, T. F. and Lund, B. M. 1985. Microbiological changes in cottage cheese varieties during storage at + $7^{\circ} \mathrm{C}$. Food Microbiol. 2:207-233.

Brooks, J. C., Martinez, B., Stratton, J., Bianchini, A., Krokstrom, R. and Hutkins, R. 2012. Survey of raw milk cheeses for microbiological quality and prevalence of foodborne pathogens. Food Microbiol. 31:154-158.

Brul, S. and Coote, P. 1999. Preservative agents in foods: mode of action and microbial resistance mechanisms. Int. J. Food Microbiol. 50:1-17.

Bullerman, L. B. 1981. Public health significance of molds and mycotoxins in fermented dairy products. J. Dairy Sci. 64:2439-2452.

Casalinuovo, F., Rodolfi, M., Rippa, P., Scognamiglio, A., Musarella, R., 2015. Abnormal colorations of mozzarella cheese caused by Phoma glomerata (Corda) Wollenw \& Hochapfel. J. Food Res. 4:19.

Colak, H. 2007. Determination of aflatoxin $M_{1}$ levels in Turkish White and Kashar cheeses made of experimentally contaminated raw milk. J. Food Drug Anal. 15: 163-168.

Creppy, E. E. 2002. Update of survey, regulation and toxic effects of mycotoxins in Europe. Toxicol. Lett. 127:
$19-28$

de Oliveira, T. M., de Fátima Ferreira Soares, N., Pereira, R. M., and de Freitas Fraga, K. 2007. Development and evaluation of antimicrobial natamycin-incorporated film in gorgonzola cheese conservation. Packaging Technol. Sci. 20:147-153.

Decker, M. and Nielsen, P. V. 2005. The inhibitory effect of Penicillium camemberti and Geotruchum candidum on the associated funga of white mould cheese. Int. J. Food Microbiol. 104:51-60.

Delves-Broughton, J., Thomas, L. V., Doan, C. H. and Davidson, P. M. 2005. Natamycin. In Antimicrobials in food. $3^{\text {rd }}$ Editions. CRC Press. 145:275.

Dermiki, M., Ntzimani, A., Badeka, A., Savvaidis, I. N. and Kontominas, M. G. 2008. Shelf-life extension and quality attributes of the whey cheese "Myzithra Kalathaki" using modified atmosphere packaging. LWT-Food Sci. Technol. 41:284-294.

El-Sharoud, W. M., Belloch, C., Peris, D. and Querol, A. 2009. Molecular identification of yeasts associated with traditional Egyptian dairy products. J. Food Sci. 74: M1-M6.

Engel, G. 1986. Vorkommen von Hefen in Frischkase-organoleptische Beeinflussung. Milchwissenschaft 41:692-694.

Esmer, O., Balkir, P. and Seckin, A. K. 2009. Changes in chemical, textural and sensory characteristics of Crottin de Chavignol cheese manufactured from frozen curd and packaged under modified atmosphere. Milchwissenschaft 64:184-187.

Fajardo, P., Martins, J. T., Fuciños, C., Pastrana, L., Teixeira, J. A. and Vicente, A. A. 2010. Evaluation of a chitosan-based edible film as carrier of natamycin to improve the storability of Saloio cheese. J. Food Eng. 101:349-356.

Fedio, W. M., Macleod, A. and Ozimek, L. 1994. The effect of modified atmosphere packaging on the growth of microorganisms in cottage cheese. Milchwissenschaft 49:622-629.

Filtenborg, O., Frisvad, J. C. and Thrane, U. 1996. Moulds in food spoilage. Int. J. Food Microbiol. 33:85-102.

Fleet, G. and Balia, R. 2006. The public health and probiotic significance of yeasts in foods and beverages. In Yeasts in Food and Beverages. 381-397. 
Fleet, G. H. and Mian, M. A. 1987. The occurrence and growth of yeasts in dairy products. Int. J. Food Microbiol. 4:145-155.

Flores, S. K., Costa, D., Yamashita, F., Gerschenson, L. N. and Grosssmann, M. V. 2010. Mixture design for evaluation of potassium sorbate and xanthan gum effect on properties of tapioca starch films obtained by extrusion. Mater. Sci. Eng. 30:196-202.

Fucinos, C., Guerra, N. P., Teijon, J. M., Pastrana, L. M., Rua, M. L. and Katime, I. 2012. Use of poly(N-isopropylacrylamide) nanohydrogels for the controlled release of pimaricin in active packaging. J. Food Sci. 77:N21N28.

Gadaga, T. H., Mutukumira, A. N. and Narvhus, J. A. 2000. Enumeration and identification of yeasts isolated from Zimbabwean traditional fermented milk. Int. Dairy J. 10:459-466.

Garabal, J. I., Rodríguez-Alonso, P., Franco, D. and Centeno, J. A. 2010. Chemical and biochemical study of industrially produced San Simón da Costa smoked semihard cow's milk cheeses: Effects of storage under vacuum and different modified atmospheres. J. Dairy Sci. 93:1868-1881.

Garnier, L., Valence, F., Pawtowski, A., Auhustsinava-Galerne, L., Frotté, N., Baroncelli, R. and Mounier, J. 2017. Diversity of spoilage fungi associated with various French dairy products. Int. J. Food Microbiol. 241:191-197.

Gurbay, A., Engin, A. B., Caglayan, A. and Sahin, G. 2006. Aflatoxin M1 levels in commonly consumed cheese and yogurt samples in Ankara, Turkey. Ecol. Food Nutr. 45: 449-459.

Haasum, I. and Nielsen, P. V. 1998. Ecophysiological characterization of common foodborne fungi in relation to $\mathrm{pH}$ and water activity under various atmospheric compositions. J. Appl. Microbiol. 84:451-460.

Hanušová, K., Št’astná, M., Votavová, L., Klaudisová, K., Dobiáš, J. and Voldřich, M. 2010. Polymer films releasing nisin and/or natamycin from polyvinyldichloride lacquer coating: Nisin and natamycin migration, efficiency in cheese packaging. J. Food Eng. 99:91-496.

Heimbecher, S. K, Jorgensen, K. V. and Price, R. L. 1988. Interactive effects of duration of storage and addition of formaldehyde on levels of aflatoxin M1 in milk. J. AOAC
Int. 71:285-287.

Hocking, A. D. 1994. Fungal spoilage of high-fat foods. Food Australia 46:30-33.

Hocking, A. D. 1997. Understanding and controlling mould spoilage in cheese. Aust. J. Dairy Technol. 52:123.

Hocking, A. D. and Faedo, M. 1992. Fungi causing thread mold spoilage of vacuum packaged Cheddar cheese during maturation. Int. J. Food Microbiol. 16:123-130.

Hymery, N., Vasseur, V., Coton, M., Mounier, J., Jany, J. L., Barbier, G. and Coton, E. 2014. Filamentous fungi and mycotoxins in cheese: a review. Compr. Rev. Food Sci. Food Saf. 13:437-456.

Korea Dairy Communitee(KDC). 2016. 유제품 유통소비현황 http://www.dairy.or.kr/jsp/layout/LayoutControlCtrl.jsp ?ACT_CD=MAIN\& INDEX_UPPERMENU_CODE=domestic \&INDEX_MENU_CODE=domestic_ani_statistics\&INDEX_ MENU_DEPTH=2

Korea Ministry of Food and Drug Safety(MFDS). 축산물의 가 공기준 및 성분규격 일부개정고시 제2016-48호.

Kure, C. 2001. Mould contaminants on Jarlsberg and Norvegia cheese blocks from four factories. Int. J. Food Microbiol. 70:21-27.

Kure, C. F. and Skaar, I. 2000. Mould growth on the Norwegian semi-hard cheeses Norvegia and Jarlsberg. Int. J. Food Microbiol. 62:133-137.

Kure, C. F., Skaar, I. and Brendehaug, J. 2004. Mould contamination in production of semi-hard cheese. Int. J. Food Microbiol. 93:41-49.

Lavoie, K., Touchette, M., St-Gelais, D. and Labrie, S. 2012. Characterization of the fungal microflora in raw milk and specialty cheeses of the province of Quebec. Dairy Sci. Technol. 92:455-468.

Ledenbach, L. H. and Marshall, R. T. 2010. Microbiological spoilage of dairy products. Compendium of the microbiological spoilage of foods and beverages, food microbiology and food safety. Springer, New York, pp. 41-67. Liewen, M. 1992. Antifungal food additives, Handbook of applied mycology. New York: Marcel Dekker, Inc.

Liu, S. Q., Asmundson, R. V., Gopal, P. K., Holland, R. and Crow, V. L. 1998. Influence of reduced water activity on lactose metabolism by Lactococcus lactis subsp. cremorisat different $\mathrm{pH}$ values. Appl. Environ. Microbiol. 64:2111-2116. 
Lopez, C., Ramos, L., Ramadan, S., Bulacio, L. and Perez, J. 2001. Distribution of aflatoxin M1 in cheese obtained from milk artificially contaminated. Int. J. Food Microbiol. 64:211-215.

López-Malo, A., Alzamora, S. M. and Palou, E. 2005. Aspergillus flavus growth in the presence of chemical preservatives and naturally occurring antimicrobial compounds. Int. J. Food Microbiol. 99:119-128.

Lourens-Hattingh, A. and Viljoen, B. C. 2001. Growth and survival of a probiotic yeast in dairy products. Food Res. Int. 34:791-796.

Lund, F. 1995. Diagnostic characterization of Penicillium palitans, $P$. commune and P. solitum. Lett. Appl. Microbiol. 21:60-64.

Lynch, K. M., Pawlowska, A. M., Brosnan, B., Coffey, A., Zannini, E., Furey, A. and Arendt, E. K. 2014. Application of Lactobacillus amylovorus as an antifungal adjunct to extend the shelf-life of Cheddar cheese. Int. Dairy J. 34:167-173.

Marshaly, R. I., Deeb, S. A. and Safwat, N. M. 1986. Distribution and stability of aflatoxin M1 during processing and storage of Karish cheese. Acad. J. Agric. Res. 31: 219-228.

Nielsen, K. F., Dalsgaard, P. W., Smedsgaard, J. and Larsen, T. O. 2005. Andrastins A-D, Penicillium roqueforti metabolites consistently produced in blue-mold-ripened cheese. J. Agric. Food Chem. 53:2908-2913.

Northolt, M. D., Van Egmond, H. P., Soentoro, P. and Deijll, E. 1980. Fungal growth and the presence of sterigmatocystin in hard cheese. J. Assoc. Off. Anal. Chem. 63: 115-119.

Oruc, H. H., Cibik, R., Yilmaz, E. and Gunes, E. 2007. Fate of aflatoxin M1 in Kashar cheese. J. Food Saf. 27:82-90.

Pitt, J. I. and Hocking, A. D. 2009. Fungi and food spoilage (3rd ed.). New York: Springer.

Polychronaki, N., West, R. M., Turner, P. C., Amra, H., Abdel-Wahhab, M., Mykkanen, H. and El-Nezami, H. 2007. A longitudinal assessment of aflatoxin M1 excretion in breast milk of selected Egyptian mothers. Food Chem. Toxicol. 45:1210-1215.

Prandini, A., Tansini, G., Sigolo, S., Filippi, L., Laporta, M. and Piva, G. 2009. On theoccurrence of aflatoxin $M_{1}$ in milk and dairy products. Food Chem. Toxicol. 47:
984-991.

Purchase, I. F. H., Steyn, M., Rinsma, R. and Tustin, R. C. 1972. Reduction of the aflatoxin M content of milk by processing. Food Chem. Toxicol. 10:383-387.

Rosi, P., Borsari, A., Lasi, G., Lodi, S., Galanti, A., Fava, A., Girotti, S. and Ferri, E. 2007. Aflatoxin M1 in milk: reliability of immunoenzymatic assay. Int. Dairy J. 17: 429-435.

Sajadi, K. and Bahramian, S. 2015. Antifungal effect of aloe vera gel on Penicillium citrinum in culture media and UF cheese. Int. J. Food Eng. 1:61-64.

Sarais, I., Piussi, D., Aquili, V. and Stecchini, M. 1996. The behavior of yeast populations in Stracchino cheese packaged under various conditions. J. Food Prot. 59: 541544.

Saxer, S., Schwenninger, S. M. and Lacroix, C. 2013. Characterization of the microflora of industrial Mexican cheeses produced without added chemical preservatives. LWT Food Sci. Technol. 53:314-320.

Sayanjali, S., Ghanbarzadeh, B. and Ghiassifar, S. 2011. Evaluation of antimicrobial and physical properties of edible film based on carboxymethyl cellulose containing potassium sorbate on some mycotoxinogenic Aspergillus species in fresh pistachios. LWT Food Sci. Technol. 44, 1133-1138.

Schillinger, U. and Villarreal, J. V. 2010. Inhibition of Penicillium nordicum in MRS medium by lactic acid bacteria isolated from foods. Food Control 21:107-111.

Sengun, I. Y., Yaman, D. B. and Gonul, S. A. 2008. Mycotoxins and mould contamination in cheese: A review. World Mycotoxin J. 1:291-298.

Swearingen, P. A., O'sullivan, D. J. and Warthesen, J. J. 2001. Isolation, characterization, and influence of native, nonstarter lactic acid bacteria on Cheddar cheese quality1. J. Dairy Sci. 84:50-59.

Taniwaki, M. H., Hocking, A. D., Pitt, J. I. and Fleet, G. H. 2001. Growth of fungi and mycotoxin production on cheese under modified atmospheres. Int. J. Food Microbiol. 68:125-133.

Tsai, W. Y. J., Liewen, M. B. and Bullerman, L. B., 1988. Toxicity and sorbate sensitivity of molds isolated from surplus commodity cheeses. J. Food Protect. 51:457462. 
Ture, H., Eroglu, E., Ozen, B. and Soyer, F. 2011. Effect of biopolymers containing natamycin against Aspergillus niger and Penicillium roquefortii on Fresh Kashar cheese. Int. J. Food Sci. Technol. 46:154-160.

Unusan, N. 2006. Occurrence of aflatoxin M1 in UHT milk in Turkey. Food Chem. Toxicol. 44:1897-1900.

Valencia-Chamorro, S. A., Palou, L., del Río, M. A. and Pérez-Gago, M. B. 2008. Inhibition of Penicillium digitatum and Penicillium italicum by hydroxypropylmethylcellulose-lipid edible composite films containing food additives with antifungal properties. J. Agric. Food Chem. 56:11270-11278.

Var, I., Erginkaya, Z., Güven, M. and Kabak, B. 2006. Effects of antifungal agent and packaging material on micro- flora of Kashar cheese during storage period. Food Control. 17:132-136.

Vivier, D., Rivemale, M., Reverbel, J. P., Ratomahenina, R. and Galzy, P. 1994. Study of the growth of yeasts from feta cheese. Int. J. Food Microbiol. 22:207-219.

Wanderley, L., Bianchin, A. and Arruda, T. P. 2013. Occurrence and pathogenicity of Candida spp. in unpasteurized cheese. Braz. J. Biosci. 11:145-148.

Westall, S. and Filtenborg, O. 1988. Unpublished. Yeast occurrence in Danish Feta cheese. Food Microbiol. 15:215222.

Yalcin, H. T. and Ucar, F. B. 2009. Isolation and characterization of cheese spoiler yeast isolated from Turkish White cheeses. Ann. Microbiol. 59:477-483. 